\title{
Altered HPA Axis Responsivity to Metyrapone Testing in Methadone Maintained Former Heroin Addicts with Ongoing Cocaine Addiction
}

\author{
James H. Schluger, M.D., Lisa Borg, M.D., Ann Ho, Ph.D., \\ and Mary Jeanne Kreek, M.D.
}

Metyrapone testing, a provocation of hypothalamicpituitary-adrenocortical (HPA) axis function, was performed in 39 in-patient subjects: 10 stable methadonemaintained former heroin addicts without ongoing drug or alcohol abuse or dependence (MM), eight methadonemaintained former heroin addicts without ongoing drug or alcohol abuse or dependence other than ongoing cocaine dependence (C-MM), and 21 normal volunteers (NV). Plasma adrenocorticotrophic hormone (ACTH) levels were determined in samples drawn at 9A.M., just before administration of $2.25 \mathrm{~g}$ metyrapone orally and 4 and 8 hours afterward. Following metyrapone, C-MM had levels of ACTH that were significantly higher than both $M M$ $(p<.05)$ and $N V(p<.01)$; whereas, $M M$ and $N V$ had levels that were comparable. Area under the plasma ACTH curves yielded similar results. This study documents hyperresponsivity to removal of glucocorticoid negative feedback associated with cocaine addiction, even in the setting of methadone maintenance for heroin addiction, which here and previously has been shown to be associated with normalization of HPA axis function.

[Neuropsychopharmacology 24:568-575, 2001] (C) 2001 American College of Neuropsychopharmacology. Published by Elseiver Science Inc.
KEY WORDS: Metyrapone; Cocaine; Methadone; Addiction; ACTH; HPA axis

Illicit opiates and cocaine continue to pose major public health threats from a number of perspectives, from the direct psychosocial consequences of addiction to these drugs to the medical consequences, ranging from overdose deaths to such longer-term considerations as infection with HIV and Hepatitis C. Although indicative of only the tip of the iceberg (given that most heroin and

From the Laboratory of the Biology of Addictive Diseases, The Rockefeller University, New York, New York, USA.

Address correspondence to: J. H. Schluger, Laboratory of the Biology of Addictive Diseases, the Rockefeller University, 1230 York Avenue, New York, NY 10021-6399.

Received May 4, 2000; revised August 1, 2000; accepted September 27,2000 cocaine users do not visit emergency rooms) Drug Abuse Warning Network data indicate that emergency room "mentions" related to heroin and cocaine use have risen steadily over the last decade (Drug Abuse Warning Network data 1999). Although pharmacotherapy with the opioid agonist methadone has been demonstrated to be a safe and effective treatment for opiate addiction (Dole and Nyswander 1965; Dole et al. 1966; Kreek 1992; NIH consensus statement 1997), and the agonists LAAM and buprenorphine are proving useful as additional treatment agents, no pharmacotherapy has been demonstrated to be specifically effective in the treatment of cocaine addiction. Furthermore, cocaine addiction is commonly seen comorbidly with, and complicates the treatment of, opiate addiction. Cocaine abuse has been demonstrated to be reduced in parallel, although not to the same degree as opiate use, in opiate 
addicts during effective methadone maintenance treatment (Borg et al. 1999) in large part because of the psychosocial benefits of long-term treatment. However, it is unknown to what extent reduction in cocaine use is a consequence of the neurobiological effects of long-term treatment with methadone in dually addicted patients.

Our group and others have hypothesized that alterations in responsivity to stress, reflected in and perhaps driven by, abnormal function of the hypothalamic-pituitary-adrenal (HPA) axis, are integral to the vulnerability to, acquisition and maintenance of, relapse to, and treatment of heroin and cocaine addictions (Kreek 1972, 1973, 1992, 1996; Cushman and Kreek 1994, Kreek et al. 1983, 1984). Alterations in HPA axis function can be assessed using a number of probes, alone or in combination, to stimulate or inhibit activity at different control points of the axis. Metyrapone is an 11- $\beta$-hydroxylase inhibitor that can be administered orally to block cortisol production in the adrenals, removing negative feedback normally exerted by endogenous glucocorticoids and providing an indirect stimulation to the axis. Metyrapone administration thus produces an HPA axis response paralleling that which is normally precipitated by stressors.

In earlier work from our laboratory, metyrapone testing has been used to assess HPA axis stress-responsivity in different stages of heroin addiction, as well as during methadone maintenance treatment. In the most common pattern of active heroin addiction, addicts administer several daily doses of this relatively short-acting opiate, resulting in multiple steep peaks in brain opiate levels. Metyrapone testing in active heroin users has demonstrated reduced HPA axis activation, with flattened or reduced circadian rhythms of adrenocorticotropin hormone (ACTH) and cortisol, and lowered basal levels (Kreek 1972, 1973, 1992, 1996; Cushman and Kreek 1974). Using the metyrapone test as an indicator of HPA axis responsivity in cocaine addicts during early and protracted abstinence, our group reported an increased responsivity, observed both in patients dependent on cocaine alone and in those who were also opiate-dependent former heroin addicts in long-term methadone maintenance treatment (Schluger et al. 1997).

In the present study, we describe apparently altered HPA axis function in methadone-maintained former heroin addicts with comorbid cocaine addiction, in comparison with both normal volunteers and with stable methadone-maintained former heroin addicts with no ongoing illicit drug use.

\section{SUBJECTS AND METHODS}

The study was approved by Institutional Review Board of the Rockefeller University Hospital General Clinical
Research Center (NIH-GCRC) with written informed consent obtained before participation and strict maintenance of confidentiality. Normal volunteers were recruited from the local community by word-of-mouth and advertisement. Methadone-maintained patients without and with ongoing cocaine dependence were recruited from local methadone maintenance clinics. Diagnoses for medical and psychiatric inclusion and exclusion criteria were made by clinical interview, physical examination, and review of laboratory and corroborative data performed by laboratory internists and psychiatrists trained in addiction medicine. Subjects underwent outpatient physician's evaluations, including general medical, psychiatric, and substance abuse histories, physical examination, chest X-ray, EKG, and laboratory testing including complete blood cells counts, serum electrolytes, creatinine, blood urea nitrogen, liver function tests, thyroid function tests, hepatitis A, B, C serologies, VDRL, urinalysis, and serum pregnancy tests in females. Patients recruited from methadone clinics gave consent to speak with counselors so that histories could be verified. Because HIV-1 infection is known to alter specific functions of the neuroendocrine systems under study, subjects were counseled about, and gave informed consent for HIV testing. Urine was collected on each of the outpatient visits and on a 24-hour basis during inpatient studies; aliquots were tested for the presence of mixed opioids, methadone, cocaine, cannabinoids, or benzodiazepines. Subjects were enrolled in the study and allowed to remain only if outpatient and inpatient urine toxicology results were negative, except for methadone in the appropriate groups, and cocaine in the cocaine-using methadonemaintained former heroin addicts.

The study population consisted of three groups: C-MM ( $n=8,7$ male, 1 female) actively cocaine-using methadone-maintained former heroin addicts who had a DSM-IV axis I diagnosis of cocaine dependence, ages 24.2 and 46.1 years (mean, SD: $31.9,7$.) of which seven were cigarette smokers, and one a nonsmoker; $\mathrm{MM}(n=$ 10, 8 male, 2 female) stabilized former heroin addicts in methadone maintenance without DSM-IV axis I diagnosis other than opiate dependence, ages 18.3 to 55.1 years $(32.3,12.2)$ (seven smokers, three nonsmokers), and NV ( $n=21,14$ male, 7 female) normal healthy volunteers ages 22.0 to 47.4 (34.1, 7.8), 10 smokers, 11 nonsmokers. Subjects were free of significant active medical problems, were HIV antibody negative, and did not meet DSM-IV criteria for an axis I diagnosis other than the specific substance-related diagnoses in the defined groups. All former heroin addicts, without or with cocaine dependence, were in a methadone maintenance treatment program for heroin dependence for a minimum of 6 months, and on the same dose of methadone for at least 1 month before the study (MM: mean methadone dose, range: 80.0 mg, 20-110 mg; C-MM: 72.5 mg, 60-90 mg). 
Patients in the C-MM group had long histories of cocaine addiction for more than 5 years, and were using cocaine heavily and regularly for at least the month before hospital admission. Five of the C-MM subjects underwent metyrapone testing on the second or third day of admission, while three subjects spent longer periods of time on the unit before testing. Thus, C-MM subjects were tested after a brief period of abstinence from cocaine in a controlled setting ranging from 1 to 25 days (median $=2$ days). Other illicit drugs and alcohol were not used to a sufficient extent to meet criteria for abuse or dependence. All subjects were medication-free (except methadone in methadone- maintained patients) for at least 7 days before the study. All subjects (from all three groups) were admitted to the hospital at least 1 day before testing.

Metyrapone testing was carried out in the subjects' hospital rooms. Subjects received nothing by mouth except water for at least 9 hours before testing. At 9:00 A.M., 2.25 grams of metyrapone (Metopirone, Novartis) was administered orally, with 30 cc of an oral antacid to minimize gastrointestinal upset. Methadone-maintained patients received their daily dose of methadone at 10 A.M., and all subjects were allowed to eat at 11 A.M.. Subjects who smoked were not permitted to do so until 1 P.M.. Plasma ACTH and cortisol levels were determined in blood sampled at 9:00 A.M. (just before metyrapone administration, and at 1 and 5 P.M. (4 and 8 hours following). Blood was drawn into sodium ethylenediaminetetra-acetic acid (EDTA) vacutainers and stored on ice for up to $40 \mathrm{~min}$ until centrifuged at $4^{\circ} \mathrm{C}$ at 3,000 rpm for $5 \mathrm{~min}$. Plasma was then removed, aliquoted, and stored at $-40^{\circ} \mathrm{C}$ until assayed. ACTH and cortisol levels were determined in duplicate by radioimmunoassay procedures, with slight modifications (ACTH: Nichols Institute, San Juan Capistrano, CA; cortisol: Diagnostic Products Corporation, Los Angeles, CA). ACTH intra- and interassay coefficients of variation were 9.4 and $15.1 \%$, respectively. Cortisol intraand interassay coefficients of variation were 2.5 and $6.0 \%$, respectively.

\section{STATISTICAL ANALYSIS}

A one-way analysis of variance (ANOVA) showed there was no significant difference in age among NV, $\mathrm{C}-\mathrm{MM}$, and MM. A two-tailed $t$-test showed there was no significant difference between methadone dose between MM and C-MM. Because distribution of sex and smoking status was not equivalent in the three subject groups, the effect of these factors on ACTH response to metyrapone was first examined in the normal volunteers among whom there were a significant number of subjects for each factor ( 7 females, 14 males; 10 smokers, 11 nonsmokers). Two-way ANOVA of area under the curve (AUC) for ACTH showed there was no effect of gender or smoking, nor was there a significant interaction, $F(1,17)<1$, in each case. Similarly, no effects of gender or smoking status were found for the cortisol response to metyrapone in normal volunteers. Cortisol levels were not determined in one subject from the C-MM group, because of a technical problem.

Because age and methadone dose were evenly distributed between groups, and gender and smoking status were found by statistical analysis not to have a significant effect on the test results within the control subjects, these factors were not used in the analyses of differences between groups.

Levels of ACTH and cortisol were each examined by a two-way ANOVA (Group by Time) with repeated measures on the last factor, followed by NewmanKeuls post-hoc tests when appropriate. Area under the curve from 9 A.M. to 5 P.M. of ACTH and of cortisol was calculated for each subject, and differences between groups were examined by one-way ANOVA. To examine the relationship between ACTH and cortisol, linear regression analysis was used.

\section{RESULTS}

Individual, mean ( \pm SEM), and AUCs for plasma ACTH levels in response to metyrapone testing for the three study groups are illustrated in Figures 1, 2, and 3.

Two-way ANOVA of plasma ACTH levels at 9 A.M. (preceding metyrapone administration) showed there was no significant difference between groups. Twoway ANOVA of plasma ACTH levels showed a significant group effect $\mathrm{F}(2,36)=5.54, p<.01$; a significant effect over time $\mathrm{F}(2,72)=34.21, p<.000001$; and a significant Group by Time interaction $\mathrm{F}(4,72)=4.44, p<$ .005. Newman-Keuls post-hoc tests showed that C-MM had greater responses than NV $(p<.01)$ as well as greater than MM $(p<.05)$; whereas, there was no significant difference between NV and MM. Similarly, one-way ANOVA of AUC for ACTH showed a significant group effect $\mathrm{F}(2,36)=6.86, p<.005$. Again, Newman-Keuls post-hoc tests showed that C-MM had greater responses than NV $(p<.005)$ as well as greater than MM $(p<.02)$; whereas, there was no significant difference between NV and MM.

Mean plasma levels of cortisol responses to metyrapone are illustrated in Figure 4. Two-way ANOVA of plasma cortisol levels showed a significant group effect $\mathrm{F}(2,34)=5.71, p<.01$; and a significant effect over time $\mathrm{F}(2,68)=56.88, p<.000001$. NewmanKeuls post-hoc tests showed that C-MM had lower plasma levels of cortisol after metyrapone administration than NV $(p<.005)$ as well as than MM $(p<.01)$; whereas, there was no significant difference between $\mathrm{NV}$ and MM. Here again, one-way ANOVA of AUC for 


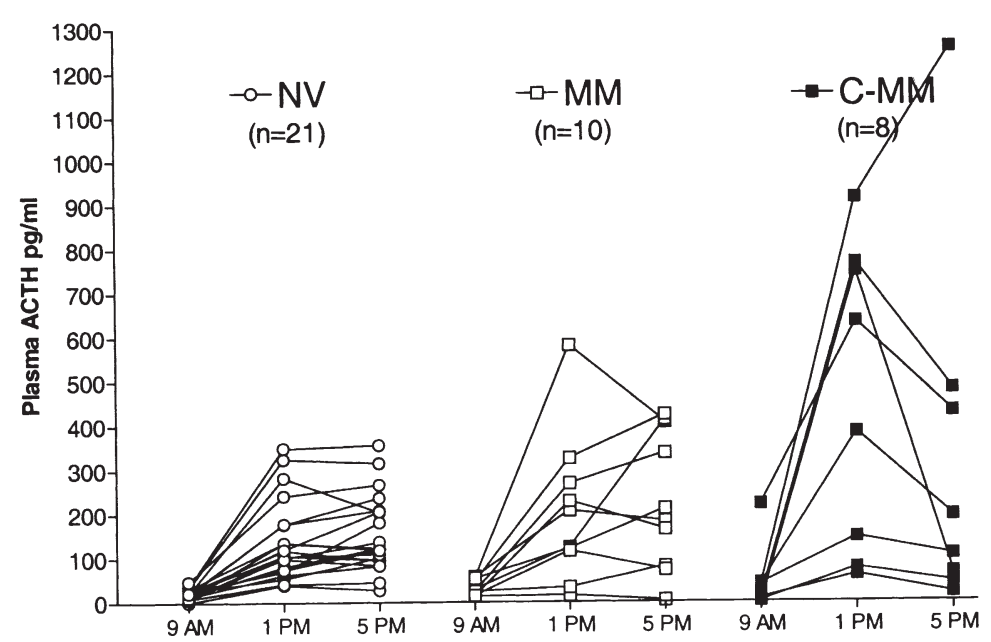

Figure 1. Individual plasma ACTH levels at 9 A.M. (just before metyrapone administration) and at 1 and 5 P.M. in NV, MM, and C-MM.

cortisol showed a significant group effect $\mathrm{F}(2,35)=4.72$, $p<.02$. Newman-Keuls post-hoc tests showed that C-MM had lower cortisol levels than NV $(p<.02)$ as well as than $\mathrm{MM}(p<.01)$; whereas, there was no significant difference between NV and MM.

When the magnitude of the reductions in plasma cortisol levels for each subject from 9 A.M. to 1 P.M. and from 9 a.m. to 5 P.M. were examined, no significant differences were found between the three groups. Also, there were no significant correlations between AUCs for cortisol and ACTH, either within each subject group, or for all subjects; that is, despite lower postmetyrapone cortisol AUCs in the C-MM, amount of cortisol suppression did not predict ACTH response. Figure 5 displays individual values for cortisol AUC plotted against ACTH AUC.

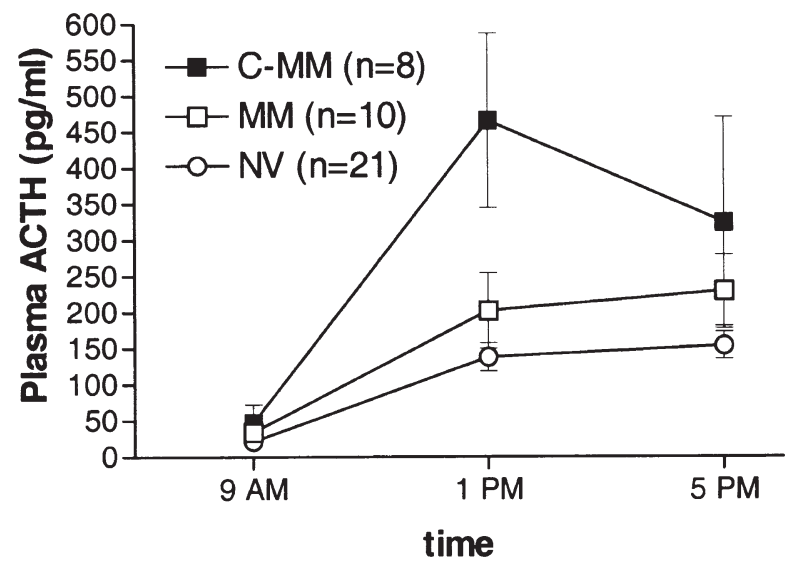

Figure 2. Mean plasma ACTH levels ( \pm SEM) at 9 A.M. (just before metyrapone administration) and at 1 and 5 P.M. in NV, MM, and C-MM.

\section{DISCUSSION}

As an orally bioavailable opiate with slow absorption and a long half-life, methadone, administered daily provides the brain with a relative steady state of exogenous opiates, compared to the "on-off" phenomena resulting from multiple administrations of rapidly distributed, short-acting, addicting opiates, such as heroin. Our group has demonstrated normalization of HPA axis function during stabilization in long-term methadone-maintenance treatment. Basal ACTH and cortisol levels were found to be within normal limits, and metyrapone testing causes HPA axis activation comparable to that observed in normal volunteers (Kreek 1972, 1973, 1992, 1996; Kreek et al. 1983, 1984). Although opiates have been shown to suppress HPA axis activity in humans acutely, and opiate withdrawal is as-

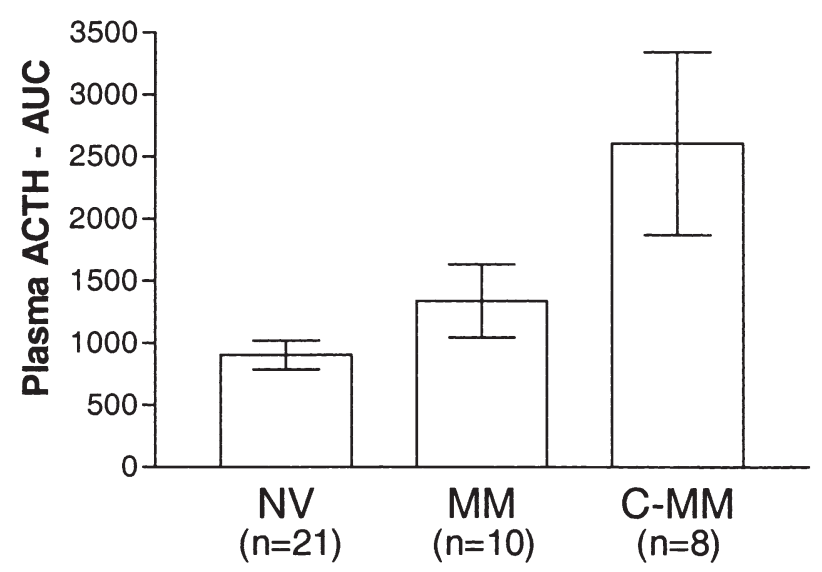

Figure 3. AUC for plasma ACTH ( \pm SEM) from 9 A.M. to 5 P.M. in NV, MM, and C-MM. 


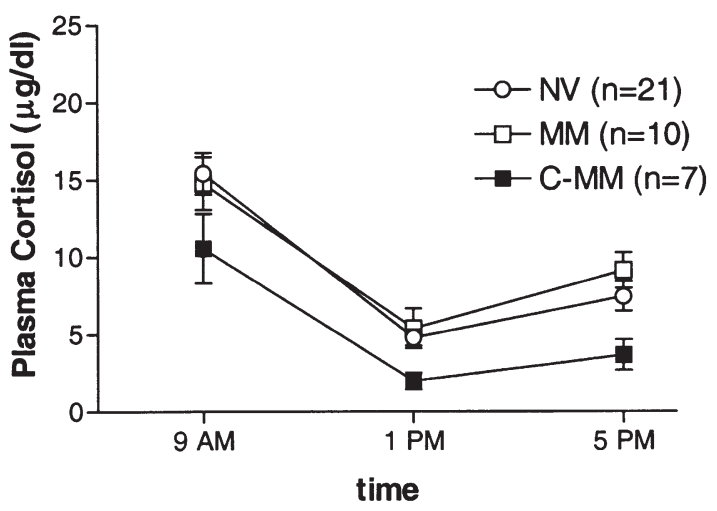

Figure 4. Mean plasma cortisol values ( \pm SEM) at 9 A.M. (just before metyrapone administration) and at 1 and 5 P.M. in NV, MM, and C-MM.

sociated with HPA axis activation, acute cocaine administration is associated with HPA axis activation (Mendelson et al. 1992a). Although basal plasma ACTH and cortisol levels have been reported to be increased in cocaine addicts on the day of hospital admission (Vescovi et al. 1992), levels of these hormones have been reported to be in the normal range after a brief period of abstinence (Mendelson et al. 1988, Baumann et al.1995).

In response to metyrapone-induced removal of endogenous glucocorticoid feedback inhibition, methadone-maintenance patients with ongoing cocaine dependence had greater HPA axis activation in the afternoon of this study than either normal volunteers or stable methadone-maintained patients with no ongoing illicit drug use, whose responses to metyrapone were comparable. In humans, in addition to interacting with serotonergic, noradrenergic, and dopaminergic systems, the HPA axis has been determined to be under inhibitory control by endogenous opioids as well as by endogenous glucocorticoids. Removal of endogenous opioid tone by the administration of opioid antagonists has been demonstrated to result in significant HPA axis activation (Volavka et al. 1979), and administration of antagonists with different opioid receptor subtype affinities suggests that endogenous kappa- and perhaps delta-, as well as mu-opioids, play a role in HPA axis control (Schluger et al. 1998). With endogenous glucocorticoid inhibitory tone removed after the administration of metyrapone, opioids play a significant inhibitory role in HPA axis function. Initially developed as a measure of pituitary reserve (Liddle et al. 1959), the response to metyrapone administration may, in part, reflect endogenous opioid inhibitory control of HPA axis function.

Previous work from our laboratory has demonstrated that the neuroendocrine responsivity to metyrapone administration is related to clinical status, with regard to active illicit drug use, abstinence, or stabilization during effective treatment. During active heroin addiction or early in methadone-maintenance treatment, when doses of methadone are increasing, the pituitary response to the removal of glucocorticoid negative feedback is blunted. However, as was replicated in the present study, during long-term stabilization in methadone maintenance, with cessation of illicit drug use, and with the accompanying decreasing preoccupation with illicit drug use seen clinically, responsivity to metyrapone administration normalizes. Furthermore, abstinence from opioids in dependent individuals is associated with HPA axis activation, which has been demonstrated to occur concomitantly (Rosen et al. 1996) or even precede subjective symptoms of withdrawal (Culpepper-Morgan et al. 1992, Culpepper-Morgan and Kreek 1997).

High rates of relapse, often stress precipitated, have been documented among opiate addicts who complete detoxification from illicit opiates and attempt to remain drug free without ongoing treatment with long-acting opioid pharmacotherapy (e.g., methadone). We hy-

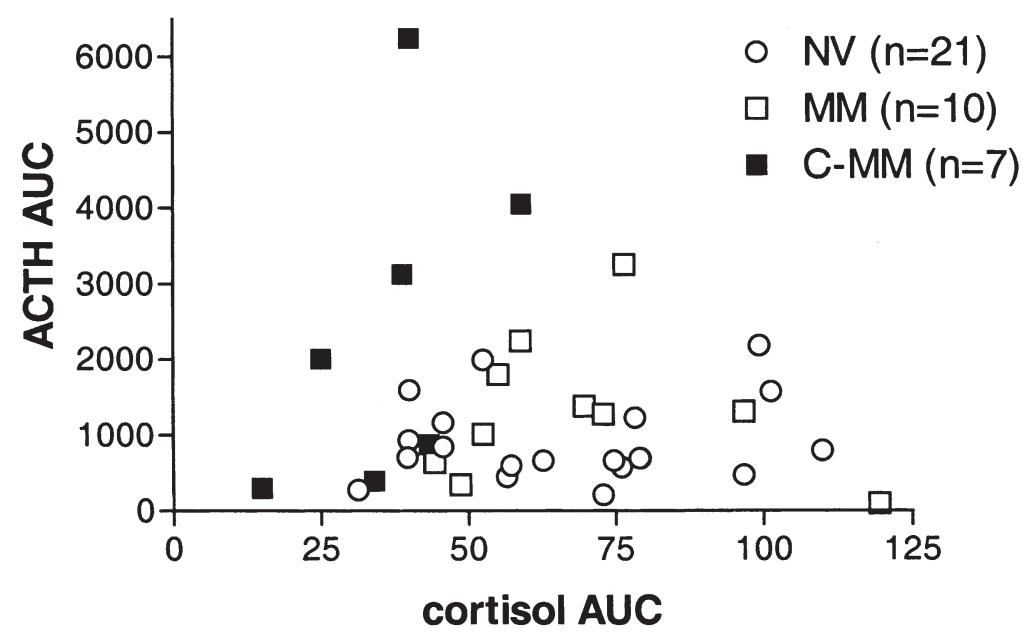

Figure 5. AUC for plasma ACTH plotted against AUC for cortisol from 9 A.M. to 5 P.M. in NV, MM, and C-MM. 
pothesize that the findings of this study may be related, in part, to alterations in opioid modulation of stress responsivity, with an inadequate opioid tone being integral to the high rates of relapse as well as to the sequelae of opiate withdrawal. Alterations in opioid control of stress-responsivity may predate and/or be a consequence of drug exposure, and may involve defects at one or more of a number of control points of opioidergic neurotransmission, including opioid peptide translation and processing, as well as receptor regulation and function. For example, our group has recently demonstrated genetic polymorphisms resulting in changes in structure and function of the mu-opioid receptor, including altered $\beta$-endorphin binding and signal transduction (Bond et al. 1998).

Although the illicit drug-free former heroin addicts in methadone maintenance in this study had responses to metyrapone comparable to normal volunteers, those who were dependent on cocaine had greatly exaggerated ACTH release. In a preliminary study, we reported previously that cocaine-dependent patients (some of whom were dependent on cocaine alone; whereas, others were illicit opiate-free former heroin addicts in methadone maintenance) had an exaggerated neuroendocrine stress response as reflected in increased release of $\beta$-endorphin after the administration of metyrapone (Schluger et al. 1997). The present study confirms this report and extends its findings, with both normal volunteers and illicit drug-free methadone-maintenance patients included as controls. Cocaine dependence, then, as with opiate addiction, may be associated with abnormal endogenous opioidergic function, in this study manifesting as exaggerated HPA axis responsivity to the removal of inhibitory glucocorticoid tone by metyrapone administration.

Interestingly, C-MM had lower postmetyrapone cortisol levels than either MM or normal volunteers. This finding is probably related to the lower baseline levels of cortisol in a group of C-MM reported in preliminary analysis of an ongoing study (Aouizerate et al. 1998), although differences in baseline were found in the afternoon of that study. Morning hormonal differences in that study were not significantly different, as in the present study. Although this might be viewed as a potential confound; that is, the greater ACTH responses seen in this group being attributable to the lower cortisol levels, there were no correlations between postmetyrapone cortisol and $\mathrm{ACTH}$, either within each subject group or for all subjects in the study. Furthermore, although cortisol levels were lower in C-MM, as a group, the amount of metyraponeinduced reduction in cortisol from 9 A.M. to 1 P.M. or 5 P.M. was comparable in all three groups. These findings indicate that rather than being attributable to the magnitude of cortisol reduction, the degree of HPA axis activation seen in this study was related to removal of all relative glucocorticoid inhibitory tone by the administration of metyrapone.

Work from our laboratory in a rodent model has demonstrated that chronic binge pattern cocaine is associated with alterations in opioid systems with changes in receptor density, as well as in gene expression of specific opioid receptors, in specific brain regions (Unterwald et al. 1992, 1994; Spangler et al. 1996; Yuferov et al. 1999). In humans, mu-opioid receptor binding detected by positron emission tomography (PET) using ${ }^{11} \mathrm{C}$-carfentanil, has been demonstrated to be increased in several brain regions of cocaine addicts, after 1-4 days of abstinence (Zubieta et al. 1996), and kappa-opioid receptor density measured autoradiographically has been demonstrated to be increased in brain tissue of cocaine overdose victims (Mash and Staley 1999).

Another brain system that may be affected by cocaine-induced alterations in opioidergic function is dopaminergic neurotransmission. Microdialysis studies in rodents have demonstrated that administration of the endogenous kappa opioid ligand dynorphin A1-17 directly to the nucleus accumbens causes a significant reduction in basal levels of dopamine in the extracellular fluid (Claye et al. 1997), and synthetic kappa opioid receptor ligands may directly reduce dopamine levels in extracellular fluid in the caudate putamen, nucleus accumbens, and related brain regions (Spanagel et al. 1990). In humans, prolactin release, under tonic inhibition by tuberoinfundibular dopamine, may be used as a peripherally accessible window into some aspects of central dopaminergic tone. Our group demonstrated that the administration of dynorphin $\mathrm{A}(1-13)$, the shortened form of the endogenous kappa opioid dynorphin $\mathrm{A}(1-17)$ resulted in elevated prolactin levels in normal human volunteers, and that this effect was mediated by a kappa opioid mechanism (Kreek et al. 1999). In a preliminary analysis of an ongoing study, our group reported on cocaine-induced alterations in opioidergic modulation of prolactin release. When dynorphin A(113) was administered to methadone-maintained former heroin addicts with ongoing cocaine addiction, prolactin release was lower than either normal volunteers or methadone-maintained former heroin addicts with no ongoing drug use (Schluger et al. 1999). Thus, cocaine administration may be associated with alterations in opioid-mediated dopaminergic tone in humans as well.

In animal models, stress has been demonstrated to reinstate cocaine seeking in drug-free, formerly cocaine-exposed animals (Erb et al. 1996). Recently, Sinha et al. have described a human experimental paradigm demonstrating personalized stress imagery-induced cocaine craving, associated with significant increases in cortisol in cocaine-dependent patients, extending the previously well-documented association between psychological stress and HPA axis activation (Sinha et al. 
1999). The HPA axis hyper-responsivity to metyraponeinduced removal of glucocorticoid negative feedback in the present study suggests that endogenous opioidergic dysfunction may be involved in the mechanism of perpetuation of, and relapse to, cocaine addiction, and reinforces lines of inquiry into novel pharmacological treatments. Corticotropin-releasing factor antagonists have been demonstrated to attenuate stress-induced drug- seeking behavior (Shaham et al. 1998) as well as IV cocaine self- administration (Goeders and Guerin 1998) in animal models. In addition, kappa opioid agonists, which may be acting to modulate cocaine- associated alterations in dopaminergic function, as well as alterations in HPA axis function, have been shown to affect cocaine self-administration and reinstatement of self-administration stimulated by cocaine exposure after a period of abstinence (Schenk et al. 1999).

Intriguingly, the partial mu agonist/kappa antagonist buprenorphine has been demonstrated to block cocaine-induced euphoria and increases in ACTH (Mendelson et al. 1992b). Although buprenorphine has proved to be a useful addition to methadone and $l-\alpha-$ acetylmethadol (LAAM) in the pharmacotherapy of opiate addiction, and may be capable of maintaining the normalization in HPA axis function associated with long-term methadone treatment (Kosten et al. 1992), its optimal role in treating opiate addiction is still being established, and there have been mixed results regarding its efficacy in reducing co-morbid cocaine addiction (Strain et al. 1994; Compton et al. 1995; Schottenfeld et al. 1997). Further understanding alterations in stressresponsive systems and their interactions with opioidergic function may, therefore, aid continued progress toward the development of novel pharmacotherapies for cocaine and opiate addictions.

\section{REFERENCES}

Aouizerate B, Schluger JH, Perret G, McClary K, Ho A, Piazza PV, Kreek MJ (1998): Enhanced sensitivity to negative glucocorticoid feedback in methadone patients with ongoing cocaine dependence. In Problems of Drug Dependence, 1998; Proceedings of the 60th Annual Scientific Meeting of the College on Problems of Drug Dependence. National Institute of Drug Abuse Research Monograph Series 179:256

Bauman MH, Gendron TM, Becketts KM, Henningfield JE, Gorelick DA, Rothman RB (1995): Effects of intravenous cocaine on plasma cortisol and prolcatin in human cocaine abusers. Biol Psychiat 38(11):751-755

Bond C, LaForge KS, Tian M, Melia D, Zhang S, Borg L, Gong J, Schluger J, Strong JA, Leal SM, Tischfield JA, Kreek MJ, Yu L (1998): Single nucleotide polymorphism in the human mu opioid receptor gene alters betaendorphin binding and activity: Possible implications for opiate addiction. Proc Natl Acad Sci USA 95:96089613
Borg L, Broe DM, Ho A, Kreek MJ (1999): Cocaine abuse sharply reduced in an effective methadone maintenance program. J Add Diseases 18(4):63-75

Claye LH, Maisonneuve IM, Yu J, Ho A, Kreek MJ (1997): Local perfusion of Dynorphin A1-17 reduces extracelluiar dopamine levels in the nucleus accumbens. In Problems of Drug Dependence, 1996; Proceedings of the 58th Annual Scientific Meeting of the College on Problems of Drug Dependence. National Institute of Drug Abuse Research Monograph Series 174:113

Compton PA, Ling W, Charuvastra VC, Wesson DR (1995): Buprenorphine as a pharmacotherapy for cocaine abuse: A review of the evidence. J Addict Dis 14(3):97114

Culpepper-Morgan JA, Inturrisi CE, Portenoy RK, Foley K, Houde RW, Marsh F, Kreek MJ (1992): Treatment of opioid-induced constipation with oral naloxone: A pilot study. Clin Pharm Ther 23:90-95

Culpepper-Morgan JA, Kreek MJ (1997): HPA axis hypersensitivity to naloxone in opioid dependence: A case of naloxone induced withdrawal. Metabolism 46:130-134

Cushman P, Kreek MJ (1994): Some endocrinologic observations in narcotic addicts. In Zimmerman E, George $\mathrm{R}$ (eds), Narcotic and the Hypothalamus. New York, Raven Press, pp 161-173

Dole VP, Nyswander ME (1965): Medical treatment for diacetyl-morphine (heroin) addiction. JAMA 193:646

Dole VP, Nyswander ME, Kreek MJ (1966): Narcotic blockade. Arch Int Med 118:304-309

Drug Abuse Warning Network, Mid-Year 1999 Preliminary Emergency Department Data. Substance Abuse and Mental Health Services Administration, Office of Applied Studies, Rockville, MD

Erb S, Shaham Y, Stewart J (1996): Stress reinstates cocaineseeking behavior after prolonged extinction and a drugfree period. Psychopharmacology 128:408-412

Goeders NE, Guerin GF (1998): Effects of CP-154,526 on intravenous cocaine self-administration in rats. In Problems of Drug Dependence; 1998; Proceedings of the 60th Annual Scientific Meeting of the College on Problems of Drug Dependence. National Institute of Drug Abuse Research Monograph Series 179:85

Kosten TR, Morgan C, Kreek MJ (1992): Beta endorphin levels during heroin, methadone, buprenorphine, and naloxone challenges: Preliminary findings. Biol Psychiat 15;32(6):523-528

Kreek MJ (1972): Medical safety, side effects, and toxicity of methadone. Proceedings of the Fourth National Conference on Methadone Treatment. NAPAN-NIMH $1972 ; 171-174$

Kreek MJ (1973): Medical safety and side effects of methadone in tolerant individuals. JAMA 223:665-668

Kreek MJ, Wardlaw SL, Hartman N, Raghunath J, Friedman J, Schneider B, Frantz AG (1983): Circadian rhythms and levels of beta-endorphins, ACTH, and cortisol during chronic methadone maintenance treatment in humans. Life Sci Suppl 133:409-411

Kreek MJ, Raghunath J, Plevy S, Hamer D, Schneider B, Hartman N (1984): ACTH, cortisol, and beta-endorphin response to metyrapone testing during chronic metha- 
done maintenance treatment in humans. Neuropeptides $5: 277-278$

Kreek MJ (1992): Rationale for maintenance pharmacotherapy of opiate dependence. In O'Brien CP, Jaffe JH (eds), Addictive States. New York, Raven Press, pp 205-230

Kreek MJ (1996): Long-term pharmacotherapy for opiate (primarily heroin) addiction: Opiate agonists. In Schuster CR, Kuhar MJ (eds), Pharmacological Aspects of Drug Dependence: Toward an Integrated Neurobehavioral Approach. Berlin, Springer, pp 487-541

Kreek MJ, Schluger J, Borg L, Gunduz M, Ho A (1999): Dynorphin A1-13 causes elevation of serum levels of prolactin through an opioid receptor mechanism in humans: Gender differences and implications for modulations of dopaminergic tone in the treatment of addictions. J Pharm Ther Exp 288:260-269

Liddle GW, Estep HL, Kendall JW Jr (1959): Clinical application of a new test of pituitary reserve. J Clin Endocrinol Metab 19:875-894

Mash DC, Staley JK (1999): D3 dopamine and kappa receptor alterations in human brain of cocaine-overdose victims. Ann NY Acad Sci 877:507-522

Mendelson JH, Teoh SK, Lange U, Mello NK, Weiss R, Skupny A, Ellingboe J (1988): Anterior pituitary, adrenal, and gonadal hormones during cocaine withdrawal. Am J Psychiat 145:1094-1098

Mendelson JH, Teoh SK, Mello NK, Ellingboe J (1992b): Buprenorphine attenuates the effects of cocaine on adrenocorticotropin (ACTH) secretion and mood states in man. Neuropsychopharmacology 7(2):157-162

Mendelson JH, Teoh SK, Mello NK, Ellingboe J, Rhoades E (1992a): Acute effects of cocaine on plasma adrenocorticotropic hormone, luteinizing hormone, and prolactin levels in cocaine-dependent men. J Pharmacol Exp Ther 263:505-509

NIH consensus statement (1997): Effective Medical Treatment of Opiate Addiction. Nov. 17-19;15(6):1-38

Rosen MI, McMahon TJ, Hameedi FA, Pearsall HR, Woods SW, Kreek MJ, Kosten TR (1996): Effect of clonidine pretreatment on naloxone-precipitated opiate withdrawal. J Pharmacol Exp Ther 276:1128-1135

Schenk S, Partridge B, Shippenberg TS (1999): U69593, a kappa-opioid agonist, decreases cocaine self-administration and decreases cocaine-produced drug-seeking. Psychopharmacology 144(4):339-346

Schluger JH, Bodner G, Gunduz M, Ho A, Kreek MJ (1997): Abnormal metyrapone tests during cocaine abstinence. In Harris LS (ed), Problems of Drug Dependence, 1997. Proceedings of the 59th Annual Scientific Meeting of the College on Problems of Drug Dependence. National Institute of Drug Abuse Research Monograph Series 178:105

Schluger JH, Ho A, Borg L, Porter M, Maniar S, Gunduz M, Perret G, King A, Kreek, MJ (1998): Nalmefene causes greater hypothalamic-pituitary-adrenal axis activation than naloxone in normal volunteers: Implications for the treatment of alcoholism. Alchol Clin Exp Res 22:1430-1436

Schluger JH, Borg L, Perret G, Ho A, Kreek MJ (1999): Dynorphin-induced prolactin release is decreased in cocaine- and methadone-maintained patients. In Harris LS (ed), Problems of Drug Dependence, 1999; Proceedings of the 61st Annual Scientific Meeting of the College on Problems of Drug Dependence. National Institute of Drug Abuse Research Monograph Series 180:90

Schottenfeld RS, Pakes JR, Oliveto A, Ziedonis D, Kosten TR (1997): Buprenorphine vs. methadone maintenance treatment for concurrent opioid dependence and cocaine abuse. Arch Gen Psychiat 54:713-720

Shaham Y, Erb S, Leung S, Buczek Y, Stewart J (1998): CP-154,526, a selective, nonpeptide antagonist of the corticotropin-releasing factor 1 receptor attenuates stressinduced relapse to drug seeking in cocaine- and heroin-trained rats. Psychopharmacology 137(2):184-190

Sinha R, Catapano D, O'Malley S (1999): Stress-induced craving and stress response in cocaine-dependent individuals. Psychopharmacology 142:343-351

Spanagel R, Herz A, Shippenberg TS (1990): The effects of opioid peptides on dopamine release in the nucleus accumbens: An in vivo microdialysis study. J Neurochem 55:1734-1740

Spangler R, Ho A, Zhou Y, Maggos C, Yuferov V, Kreek MJ (1996): Regulation of kappa opioid receptor mRNA in the rat brain by "binge" pattern cocaine administration and correlation with preprodynorphin mRNA. Mol Brain Res 38:71-76

Strain EC, Stitzeir ML, Liebson IA, Bigelow GE (1994): Buprenorphine versus methadone in the treatment of opioid-dependent cocaine users. Psychopharmacology 116(4):401-406

Unterwald EM, Horne-King J, Kreek MJ (1992): Chronic cocaine alters brain $\mathrm{mu}$ opioid receptors. Brain Res 584:314-318

Unterwald EM, Rubenfeld JM, Kreek MJ (1994): Repeated cocaine administration upregulates kappa and $\mathrm{mu}$, but not delta, opioid receptors. Neuroreport 5:1613-1616

Vescovi PP, Coiro V, Volpi R, Passeri M (1992): Diurnal variations in plasma ACTH, cortisol, and beta-endorphin levels in cocaine addicts. Horm Res. 37:221-224

Volavka J, Cho D, Mallya A, Bauman J (1979): Naloxone increases ACTH and cortisol in man. $\mathrm{N}$ Engl J Med 300:1056-1057

Yuferov V, Zhou Y, Spangler R, Maggos CE, Ho A, Kreek MJ (1999): Acute "binge" cocaine increases mu opioid receptor mRNA levels in areas of the rat mesolimbic mesocortical dopamine system. Brain Res Bull 48(1): 109-112

Zubieta JK, Gorelick DA, Stauffer R, Ravert HT, Dannals RF, Frost JJ (1996): Increased mu opioid receptor binding detected by PET in cocaine-dependant men is associated with cocaine craving. Nat Med 2(11):1225-1229 